courage maximum participation by European political and social scientists and to lessen the possibility that biopolitics will be perceived as associated almost entirely with American political science.

On this point, I am happy to report, Professor Heiner Flohr of Dusseldorf University has been extremely active in encouraging interest in biology and politics among West German political scientists. Professor Flohr organized a symposium of several days duration held in Loccum and attended by a substantial number of academics in West Germany. Papers on various aspects of biopolitics were presented both by "native" scholars and by a trio of visiting Americans, Professor Steven Peterson, Glendon Schubert, and Albert Somit.

There has been in addition an increasing interest in "biopolitics" manifest in the USSR. Professor Vladimir Denisov of the USSR Academy of Sciences played an active role at the 1979 Moscow panel sessions, has since written extensively on a Marxist approach to biopolitics, and is expected to be one of the panelists at the forthcoming Rio sessions.

As the above suggests, we are always eager to identify and involve in our efforts political scientists around the world. The IPSA Biology and Politics Research Committee would welcome the names of those with such an interest.

Albert Somit Southern Illinois University

\section{Report From The Methodology Committee}

One of the distinguishing features of the Association for Politics and the Life Sciences is the exploration of methodological approaches as well as data-gathering techniques not commonly used in political science. To date, the sharing of experiences among persons engaged in such research has been mostly informal.
Although this is very valuable for the participants, it cannot reach the wider audience that might be interested in the techniques some of us are using. In part, the effort required is one of disseminating information about how these methodologies and techniques can be applied to political behavior and about what the potential pitfalls and advantages are.

For the most part, however, we have taken methods developed in other disciplines and have used them with only slight modifications. This is not uncommon in the social sciences, and it is probably unrealistic to expect any substantial methodological innovations in the near future. However, favorable conditions for such creativity will be established if those of us engaged in empirical work make more of an effort to share our ex. periences--especially with graduate students and new professionals. In this connection, three events should be noted.

At the 1981 meeting of the American Political Science Association, APLS sponsored a workshop on methods in nonparticipant observational research. Carol Barner-Barry (University of Maryland, Baltimore County) began the panel with a paper titled, "An Introduction to Nonparticipant Observational Research Techniques." Benson Ginsburg (University of Connecticut) then presented "The Applicability of Ethological Techniques to Research on Humans." Glendon Schubert (University of Hawaii-Manoa) followed with "Potential Applications of Observational Research in Political Science." Finally, Brian Hill (University of Connecticut) demonstrated the use of a portable, computerized event recorder.

At the 1982 meeting of the American Political Science Association there will be a panel titled, "Research Methods and the Life Sciences." Currently, two presentations are planned. Steven A. Peterson and Robert Lawson (Alfred University) will give a paper titled, "Cognitive Psychology and the Study of Politics." James N. Schubert (Alfred University) will be discussing "Ethological Methods for Analyzing Interaction Process in Small Group Legislative Decision-Making."
Finally, Meredith W. Watts has edited an issue of New Directions for Methodology of Social and Behavioral Science (Number 7, 1981) titled, "Biopolitics: Ethological and Physiological Approaches." Included are contributions by Glendon Schubert, Fred Strayer, Carol Barner-Barry, Roger Masters, Meredith Watts, and Leonard Hirsch and Thomas $\mathrm{C}$. Wiegele. The volume is intended to serve as an overview of both the area and some of the problems particular to this approach. It should be useful both for those who are currently working in the area and for those who would like a reasonably comprehensive methodological introduction.

Carol Barner-Barry University of Maryland, Baltimore County

\section{Report From The Public Policy Committeo}

For this first issue of Politics and the Life Sciences, the most useful report on the subfield concerned with the public policy aspects of biopolitics would be identification of its scope and focus. The paragraphs that follow describe one view of this biopolitical subfield, but readers may have other perspectives. Therefore this report is also an invitation to readers to add their comments, objections, or qualifications to these observations. In a subfield as dynamic as biopolitics, there can be no final word on any subject.

It is characteristic of biopolitics that its subfields are not discrete--not neatly separable. Policy, in particular, interrelates to all other aspects of the subject. Biopolitical issues may arise as philosophical or theoretical propositions and move from conjecture to empirical research. Research findings may imply commercial application, or they may suggest public action perhaps to facilitate, regulate, or even prohibit the further develop- 
ment of biological knowledge or technique. At this last sequential stage at which some form of official public action is indicated, policy implications have often developed to a point of feasible inquiry. There is seldom a clearly marked threshold when an issue passes from the political stages of conceptual formulation and legislative action to the confirmation of a public policy.

Policy is a vaguely bounded concept, but I take it to mean both what is intended and what is done in the name of public authority. In recent times the conventional agents of policy have been governments and intergovernmental agencies. Historically, of course, churches, religious brotherhoods, and private corporate bodies for trade and development have made public policy. Yet I believe that we should not assume that the concept policy is axiomatic, understood by everyone, and in need of no examination. Questions of definition and semantics often lead to sterile debate, but this need not be the outcome of serious inquiry into important but diffuse ideas.

During the past two centuries, the state has become the predominant policymaker, but its primacy appears to be waning. A phenomenon of our times is the growing complexity of the public policy process. At all levels of the process of governing--local, national, and international--nongovernmental organizations are becoming increasingly involved, not only in the politics of policy choice, but in the actual formulation and implementation of public policies. Thus both the environment and process of policy formation is changing, and the association of policy with government through the mechanism of the political state is not as clear as it has been. Politics has expanded beyond the polis to become a generalized process of social decision-making.

The expansion of the life sciences and their associated technologies has greatly enlarged the scope and complexity of biopolitical policy studies. It is becoming difficult to find a public issue that does not have somewhere within it a bioscience component. Thus, there will be little reward in seeking a precise focus for the policy subfield of biopolitics (however policy is defined). The dynamics of biobehavioral research preclude it. Individual research efforts may be as sharply focused as their subject matter permits; very often it will not permit great precision. The diversity of the subjects and circumstances of policy suggests that no particular set of methods is exclusively appropriate to its study.

The development and implementation of policy is an ongoing process. The innovative, dynamic, and complex character of the biopolitical field of inquiry suggests that one function of the Association for Politics and the Life Sciences is consideration of the development of a system for monitoring the course of policy development on at least the salient biopolitical issues. From such effort it is possible that collegial strategy for policy research might be developed that would enhance the prospects for subject matter coverage and productive inquiry in this subfield.

At least one sector of inquiry into biopolitics and public policy should join analytic methods to hypothesis construction and conjecture. It seems to me that focus here should be on possible consequences of alternative policies. In open democratic societies policymaking appears more often to be reactive than anticipatory. Policies and programs are adopted on what are believed to be their intrinsic merits with little inquiry into their collateral and longer-range consequences.

Progress in bioscience has frequently led to unanticipated developments with which societies have been unprepared to cope. Examples are numerous and well-known. Sanitation and medicine brought death control to traditional societies with no attempt to alter birth rates. Birth control technologies reached a level of reliability and accessibility that has profoundly influenced the structure of modern society. Advancements in geriatrics, combined with birth control, are altering the age distribution in society and undermining established policies regarding social insurance and employment. Governments and social institutions generally have failed to anticipate problems which could have been foreseen.
The policy focus of biopolitics could provide, among other contributions, early warning of problems latent in biobehavioral innovation. To this end, systematic scanning of emergent developments for possible synergistic relatedness is needed. Here biopolitical researchers may benefit from the work of the more reliable futurologists and technological forecasters. However, to avoid the utopian taint that has too often diminished the value of conjectural studies, biobehavioral investigators need solid and realistic grounding in whatever knowledge is available regarding patterns and tendencies of human behavior. For all its deficiences, recorded human experience should be drawn upon in estimating the probable human responses to innovations that have an impact on the most basic aspects of interpersonal and collective human association.

The rapidly expanding areas of in formation and communication science and technology are certain to join with biomedical develoments in synergistic ways. Biopolitical studies, and especially their policy aspects, advance toward a receding horizon of knowledge. An expanding terrain thus opens for exciting and in novative work.

Lynton Caldwell Indiana University

\section{Report from the Curriculum Committeo}

The Associaton of Politics and the Life Sciences sponsored a curriculum workshop at the 1981 meeting of the American Political Science Association. Participants were Benson Ginsburg (University of Connecticut), Samuel Hines (College of Charleston), Glendon Schubert (University of Hawaii), John Wahlke (University of Arizona), Herbert Wilcox (West Virginia University), Fred Willhoite (Coe College), Elliott White (Temple University), and Thomas C. Wiegele (Northern Illinois 